\title{
Clary Sage Oil
}

National Cancer Institute

\section{Source}

National Cancer Institute. Clary Sage Oil. NCI Thesaurus. Code C107293.

The essential oil of Salvia sclarea. Clary sage oil is used in the treatment of depression, stress, insomnia and deep seated tension. 